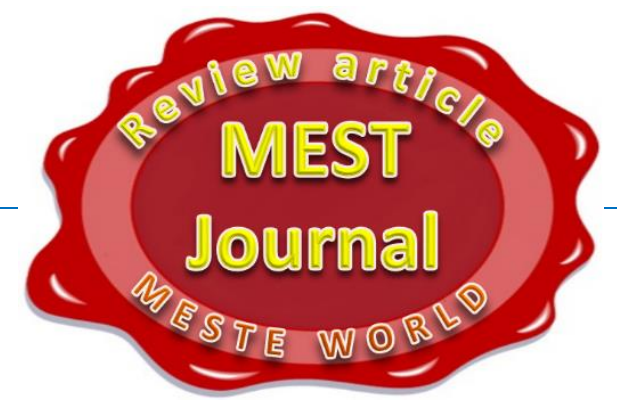

\title{
PROSPECTS FOR THE IMPLEMENTATION OF BLOCKCHAIN TECHNOLOGY IN RUSSIA
}

\section{Evgeny Safonov}

Branch of the Russian State Humanitarian University in Domodedovo, Russia

\section{Sergey Kirsanov}

Branch of the Russian State Humanitarian University in Domodedovo, Russia

\section{Galina Palamarenko}

Branch of the Russian State Humanitarian University in Domodedovo, Russia

CMESTE

JEL Category: L86, 033

\begin{abstract}
This article explores the best practices of the use of distributed registry technologies that are currently in place in different countries, formulates proposals for the use of blockchain technologies in Russia. Blockchain technology has enormous potential for applications in sectors such as banking, finance, management, and cybersecurity. This technology can be applied in the field of healthcare to solve the problem of reliability and confidentiality of the information and improve the quality of medical services. The scope can be maintained by registers, cadasters, etc. The article substantiates the need for the development of state regulation of distributed registry technologies. The work provides examples of the implementation of blockchain technologies in various sectors of the economy, including in the field of public administration and the provision of public services. It is noted that the current state of the legal framework for the use of blockchain technologies in Russia is at the initial stage of development. It is concluded that blockchain technology, being an effective tool on its basis, contains relevant solutions to the problems of the digitalization of the Russian economy. This indicates the serious potential of blockchain technologies, and there is every reason to believe that blockchain will become one of the most important components of the emerging digital economy and those innovations that will take the development of Russia to a fundamentally new level.
\end{abstract}

Keywords: blockchain technology, digital economy, distributed registry

\section{SETTING OF A PROBLEM}

Address of the corresponding author:

Sergey Kirsanov

恝ksaimr@mail.ru
The report of the World Economic Forum (WEF) gave the following definition of blockchain technology or distributed ledger technology (DLT): it is a technological protocol that allows direct data 
exchange between various contracting parties within the network without the need for intermediaries. (Bosenko, 2019)

A Cisco study says that by 2021 , the blockchain market will be capable of reaching $\$ 9.7$ billion. By $202710 \%$ of global GDP will be stored in blockchains due to the rapid development of technology. According to Cisco and IDC, the blockchain industry will grow at an incredible pace, as it lays the foundation for the development of the so-called programmed economy, which is projected to reach $\$ 3$ trillion by 2030 . The big driving force in this revolution is related to the growth of the API economy and the way technology is used in corporate business. Despite the technological development, methods of operating a business through the Internet are facing new challenges. Today's organizations are increasingly facing processes of managing data and transactions between many unreliable parties. It follows from this that blockchain technologies should first solve the tasks of transparency, complexity, and security.

The current interest in blockchain technology is because two approaches are used to ensure the reliability of the information, and each of them matters if there is another, namely:

1. Proof-of-Work - participants in the transformations solve cryptographic problems of changing complexity. The more information resources on the network, the more difficult the task. This approach led to a craze for mining in the world of cryptocurrencies.

2. Proof-of-Stake - participants do not solve cryptographic problems but validate transactions by "freezing" as a mechanism for confirming ownership of this good. When an agreement is reached on the network, transactions are added to the blockchain, when defrosting, the miner gets back the amount with a commission for recording the transaction on the blockchain. (Belokrylova \& Goncharova, 2019)

As for the main advantages, special attention should be devoted to the following of them: the trust of Blockchain entities to each other, eliminating external interference in the system; constant open access to the possibility of control over the operations performed "from within", that is, by the system users themselves; stability of the integrity of the stored data due to the distributed storage system, which does not allow the performance of data without the consent of all entities involved in the data chain; increasing transaction speed.

As for the thread of use of the blockchain, experts identify the following areas:

- finance.

- banking.

- management of land and property complexes (both at the regional and municipal levels).

- healthcare.

- logistics.

- trading.

- construction and others.

The advantage of the blockchain, first of all, as a reliable way to ensure the security of the transmission, use, and storage of information in a huge network of interconnected elements, is determined by the need for synchronized changes in each of them, the identification of dangerous software using hash functions, etc. The most certain advantage of the blockchain, in our opinion, is its definition as the Internet of things. Security in the context of information is currently associated with this technology to a large extent.

The impossibility of gaining access immediately to all the components of the chain, where each of them contains the necessary information, the lack of the possibility of the inverse transformation to obtain the initial code - these are some of the components of reliability.

Transparency is another advantage of the blockchain.

The use of blockchain technologies in the design and operation of smart cities, the creation of which is receiving increasing attention in many countries of the world, is crucially important, in our opinion. So, smart healthcare can only work on the principles of this technology discussed above. The preservation of patients' data, the impossibility of changing them, falsification, using for criminal purposes is a solution to social, economic, and moral-ethical problems in this area. This becomes fundamentally important in the face of the emergence of new threats to humanity when the prompt use of reliable information determines not only national security. 
Smart transport. If we consider only a part of it, namely, haulage, it should be noted that in this industry various types of transport are combined into a complex network distributed all over the world. Blockchain in transport routes allows you to reduce costs and time, increase competition, reduce the likelihood of errors and risks. The introduction of blockchain in logistics requires the creation of standards in the field of transportation. Currently created platforms (for example, ship chain) allow you to track the location of the cargo, and this information is available only to official participants in the process.

In Russia, the blockchain has been widely used in complex, large trading networks that have created independent decentralized systems that can reduce costs while increasing the reliability of the provision of goods to individual units. Of interest is the Factorin platform, which was created for the Dixie group of companies, and the development and implementation required only a year and a half and gave positive results. The transition to this platform will reduce the need for partners in working assets because in this case, banks and factoring campaigns take over the lending function. All this allows, among other things, to reduce transaction costs.

We should separately highlight the problem of smart contracts that are still not widespread in Russian business and worked out from the point of sight of the law. Identification of the terms of the contract and the actions performed by the parties to the contract allows for automatic payments, transfer of ownership, currency exchange, and other operations. Virtual agreements on the rigidity of control, including due to the maximum reduction of the human factor, the obligation to fulfill the originally pledged obligations, surpass traditional forms.

The use of blockchain technologies can be significantly hampered by an insufficient elaboration of legal issues, namely patenting the results of intellectual activity. Many questions will arise if you need to use several technologies. The prospect of such a combination is undeniable.

Particularly acute is the competition for the possession of the rights to commercialize the development results in the United States, where blockchain technologies are most developed. Most likely, patent holders will act not only for protection but will also transfer the patents they receive to consortia that seek to facilitate the implementation of blockchain in the financial sector. Thus, patent protection will become an integral element in the development of blockchain technology.

We note the traditionally weak position of the developers of the Russian Federation in the global patent business, which today is an inhibiting circumstance in the issues of security of the proposed blockchain algorithms.

Thus, Blockchain technology is one of the bricks in the foundation of the new formation, and the future position on the world stage and the role in global relations depend on how actively the state will contribute to its implementation.

\section{EXPERIENCE IN IMPLEMENTING BLOCKCHAIN TECHNOLOGY IN OTHER COUNTRIES}

Estonia is the leading country in adopting blockchain technology primarily in healthcare and property management. Citizens and residents of Estonia can use cryptographically secure digital ID cards equipped with blockchain infrastructure, which provides access to various public services. On the blockchain platform, users can verify the safety of personal information located in state databases. Voting by members of stock companies is also possible through the blockchain. (Tsvetkova, 2017)

Estonia is one of the leading countries in the field of cybersecurity, state subsidies go to the development of many projects that make it possible to simplify the use of public services by citizens as much as possible. (e-estonia, 2020)

The E-Estonia program covers such global spheres of life and society as:

- Electronic identification (ID-cards, Mobile IDs, Smart-ID, "Electronic Resident").

Internal operational services (X-Road, Land Register, Population Register).

- Security (Electronic Signature System, Electronic Justice, Electronic Law, Electronic Police).

- Healthcare (Health Register, Electronic Ambulance, Electronic Prescriptions for Medicines). 
- Government services (Government Cloud, Information Embassy, Electronic Voting, Government Meeting Information System).

- Mobile services (Smart Transportation System, Mobile Parking, Landing Queue Manager).

- Doing business and finance (Electronic tax, Electronic banking, Electronic business registry).

- Education (Estonian Educational Information System, E-school, E-portfolio) and others.

Briefly describing the system for the provision of electronic services that has been formed to date in Estonia using Blockchain technology, it is necessary to note the fact that it is the concentration of these services within the framework of an integral state project that allows Estonia to maintain decades of global pace. After analyzing the structure of services, on can note that similar projects are presented in many countries of the world, but it is precisely the systematic nature that gives the Estonian experience uniqueness.

The city of Seoul for the Republic of Korea is, literally, a litmus test in the application of various technologies and innovations. Being the capital of the state, Seoul was chosen as the center for the initial implementation of Blockchain technology in the everyday life of citizens.

On the territory of the city, large-scale programs for working in the information and management field have been launched, which include smart metro projects, projects to minimize the cost of unprofitable transport, solve the multi-factor taxi problem, minimize traffic accidents involving children and older people, the smartphone-for everyone ", as well as the u-Seoul Safety Service, which contribute to Seoul's technology system.

When making this or that decision, a huge number of indicators are considered, which, together with a well-established system of civic inquiry, give the city's socio-economic growth as a result.

New technologically and advanced services are being tested at Living Lab. Also, the decision to abandon or eliminate an innovation is not made by officials, but by a community of citizens who may be affected by the changes through the M-Voting voting system. (pwc, 2015)
As a result of a careful collection of statistical data, one can judge the changes occurring from a project. For example, having formed a system of night routes, Seoul can serve as a good example of the effects of the implementation of Blockchain projects. Thus, the creation of 9 optimal night routes, considering the load on transport hubs, reduced the number of vehicles used at night to 50 buses.

The following can be considered as examples of initiatives by some governments of the application of blockchain technologies. In November 2019, Indian Minister of Electronics and Information Technology Sanjay Dhotre announced the launch of a national blockchain deployment program in the country. The Government of India has already allocated \$900 thousand to launch a project called the Distributed Blockchain Technology Center of Excellence, which will bring together the Center for Advanced Computing Development (CDAC), the Institute for Development and Research in Banking Technologies (IDRBT) and the Institute of Technology Veermata Jijabai (VJTI). The project is aimed at the development and pilot implementation of blockchain solutions.

The Indian state of Telangana is already testing a blockchain platform for registering property. Although landowners have noted the clear benefits of blockchain that make it easier to obtain documents, the problem of corruption remains. The data stored in such a system cannot be changed after entering, but so far, no way has been found to prevent government officials from entering deliberately incorrect information.

In India, the Proof-of-Existence (PoE) blockchain structure will be used to authenticate diplomas, certificates, contracts, and other documents. Also, the PoE platform can be used to control vehicles and hotels. (Ivanov, 2019)

Blockchain in Great Britain. Blockchain found practical application in the work of state bodies when registering transactions related to social security. It is believed that blockchain can help in areas such as reducing fraud, protecting critical infrastructure, and registering assets.

Blockchain is accepted for use in management systems in countries such as Finland, Singapore, Dubai, Switzerland, and this list will only increase. (Tsvetkova, 2017) 


\section{IMPLEMENTATION OF BLOCKCHAIN TECHNOLOGY IN THE RUSSIAN FEDERATION}

In the Russian Federation, the use of blockchain technology to maximize the creation and development of the digital economy is established in the Digital Economy of the Russian Federation Program. The government supports development, including through pilot projects to protect the results of intellectual activity in the field of the digital economy. It should be noted that back in 2016, a working group of the Central Bank of Russia was formed to study the prospects for introducing new technologies in the financial sphere. In the same year, it was announced about the creation of the Central Bank of the Fintech blockchain consortium in partnership with the ten largest banks in Russia, for "... a comprehensive study of the technology of distributed registries and their capabilities. The consortium is created in the form of an association. Among the goals of the consortium are technological, regulatory, practical, and communication. (Tsvetkova, 2017)

A center was created at the National Research Nuclear University MEPhl whose main goal is to create its blockchain technology platform and applications for industries.

It should be noted that many companies have signed agreements on the creation, implementation, and promotion of blockchainbased technology products. The technologies under consideration provide a trusting relationship due to the reliability and safety of information because errors or fraud are not possible without stating them. (Ivanov, 2019)

Sberbank of Russia carried out 15 pilot projects, some of which found practical application. For example, it is planned to use the blockchain platform for processing real estate transactions. German Gref, Chairman of the Board of Sberbank, noted that to use this technology, it is necessary to amend the Russian legislation the Federal Law "On Personal Data". (Bulgatova \& Sandakov, 2018)

Blockchain technologies have prospects for widespread use in voting. The first such experience in Russia was successfully acquired when testing the Blockchain with the holding of the meeting of bondholders of the National Settlement Depository. (Belokrylova \& Goncharova, 2019)

In 2019, the Skolkovo Foundation and Waves created a blockchain center, the purpose of which is to help businesses and government agencies to implement distributed registry technologies.

By generating ideas on the practical application of the blockchain, testing them, prototyping, supporting promising startups, and helping businesses to implement the blockchain, the center expects to popularize this technology in the country. Waves Enterprise, the Waves Enterprise unit focused on corporate projects, will deal with expert and analytical support for the blockchain center. Skolkovo and Waves expect the company's customers and partners to be large companies and departments in which bureaucratic and business processes can be simplified using technology. The center is going to invite world experts on the use of blockchain in business in Russia and organize its educational programs. (Ivanov, 2019)

These advantages give reason to think about the need to accelerate the transfer of technology in large volumes to areas that go beyond the usual notion of Blockchain, for example, in areas related to state and municipal administration. Several projects are proving that the application of Blockchain order technologies opens new opportunities for a society that government agencies are not able to give in the usual sense.

Using blockchain technologies will achieve significant results:

- in the field of technology (independence from foreign developments in financial infrastructure; maintaining confidentiality, including the number of medical data; increasing the security of state information systems).

- in the field of economics (obtaining significant economic direct and indirect effects by increasing GDP, reducing costs and losses).

- in the social sphere (accessibility of services, including banking, improving the quality of public services, increasing the level of services to the public, including medical).

Considering the specific prospects for the introduction of technology in Russia, it is necessary to highlight the conceptually promising 
and most likely projects for early implementation. (Butusov, 2019)

These should include, first, the implementation of Blockchain in the activities of portals providing state and municipal services. One of the primary and socially significant projects in this area may be the reform of the existing queuing system for social benefits, which includes queues for kindergartens and other educational institutions, as well as subsidiary queues.

Building a system of social queues based on a distributed data registry will at least simplify the process of transferring data to the conduct of similar departments when changing places of residence, as well as monitor all processes occurring within the queue.

These measures can minimize the cost of transferring data from one territorial unit to another, as well as reduce the burden on the employees of departments. Also, this "ferry" system would reduce paperwork, which is still the scourge of Russian office work.

For a comprehensive solution to the problem of transferring from one territorial unit to another, it is necessary to create a concomitant system for assessing and analyzing personal data, as well as data on the previous position in the queue, etc., which would help determine the position in the new queue.

\section{CONCLUSION}

The introduction of technology at the level of state structures should be accompanied by a multivariate analysis of the advantages and disadvantages, and the economic assessment of the expected results based on the principles of saving budget funds and the profitability of these measures should also serve as a basis.

Today in Russia there is a relatively large body of successful mathematicians and programmers, in this regard, the development of blockchain technology may allow Russia to gain an advantage over other countries

The undoubted advantage of Russia is lower electricity prices compared to a sufficiently large number of countries, which is becoming increasingly important with increasing energy costs necessary for the operation of blockchain technologies

We would like to note that the blockchain has every reason to become the main driving force for the development of both the digital economy and the country's economy. There are a large number of problems both tactical and strategic levels that need to be addressed quickly. Significant financial resources will be required for complex, systemic transformations.

A review of Russian developments gives reason to note their rather high competitiveness, unique staffing, which gives reason for a positive outlook on the development of blockchain technologies in Russia.

\section{WORKS CITED}

Belokrylova, O., \& Goncharova, Y. (2019). Blokcheyn kak effektivnyy instrument soglasovaniya ekonomicheskikh interesov faktorov tsifrovoy ekonomiki Rossii. Voprosy regulirovaniya ekonomiki, 10(1), 51-63.

Bosenko, T. (2019). Razvitiye oblasti primeneniya sistem blokcheyn v sovremennoy ekonomike. Ekonomika: vchera, segodnya, zavtra, 9(3A), 264-269. Retrieved from http://publishingvak.ru/file/archive-economy-2019-3/28-bosenko.pdf

Bulgatova, Y., \& Sandakov, B. (2018). Blokcheyn-tekhnologiya kak novyy put' razvitiya ekonomiki Rossii. Vestnik buryatskogo gosudarstvennogo universiteta ekonomika i menedzhment, 1, 1622.

Butusov, A. (2019, Oct 14). Ekonomicheskiy effekt ot blokcheyna $v$ Rossii dostignet $k 2024$ godu 1,6 trln rubley ot 14.10.2019/. Retrieved from iot.ru: https://iot.ru/promyshlennost/ekonomicheskiyeffekt-ot-blokcheyna-v-rossii-dostignet-k-2024-godu-1-6-trln-rubley 
e-estonia. (2020). we have built a digital society and we can show you how. Retrieved from e-estonia: https://e-estonia.com/

Ivanov, A. (2019). Waves protocol. Retrieved from waves: https://www.tadviser.ru/index.php/\%D0\%9A\%D0\%BE\%D0\%BC\%D0\%BF\%D0\%B0\%D0\%BD \%D0\%B8\%D1\%8F:Waves_Protocol_(\%D1\%80\%D0\%B0\%D0\%BD\%D0\%B5\%D0\%B5_Wave s_Platform)\#.D0.98.D1.81.D1.82.D0.BE.D1.80.D0.B8.D1.8F

pwc. (2015, May 02). Golosovaniya sredi gorozhan: opyt gorodov mira. Retrieved from Higher School of Economics - National Research University: https://www.hse.ru/data/2017/04/25/1171674157/\%D0\%93\%D0\%BE\%D0\%BB\%D0\%BE\%D1 \%81\%D0\%BE\%D0\%B2\%D0\%B0\%D0\%BD\%D0\%B8\%D1\%8F\%20\%D1\%81\%D1\%80\%D0\% B5\%D0\%B4\%D0\%B8\%20\%D0\%B3\%D0\%BE\%D1\%80\%D0\%BE\%D0\%B6\%D0\%B0\%D0\%B D.pdf

Tsvetkova, L. A. (2017). Perspektivy razvitiya tekhnologii blokcheyn v Rossii: konkurentnyye preimushchestva i bar'yery. Ekonomika nauki, 3(4), 275-296.

Received for publication:

Revision received:

Accepted for publication:
11.03.2020

07.05 .2020

01.07 .2020

\section{How to cite this article?}

Style - APA Sixth Edition:

Safonov, E., Kirsanov, S., \& Palamarenko, G. (2020, July 15). Prospects for the implementation of blockchain technology in Russia. (Z. Cekerevac, Ed.) MEST Journal, 8(2), 157-163. doi:10.12709/mest.08.08.02.18

Style - Chicago Sixteenth Edition:

Safonov, Evgeny, Sergey Kirsanov, and Galina Palamarenko. 2020. "Prospects for the implementation of blockchain technology in Russia." Edited by Zoran Cekerevac. MEST Journal (MESTE) 8 (2): 157-163. doi:10.12709/mest.08.08.02.18.

Style - GOST Name Sort:

Safonov Evgeny, Kirsanov Sergey and Palamarenko Galina Prospects for the implementation of blockchain technology in Russia [Journal] // MEST Journal / ed. Cekerevac Zoran. - Belgrade Toronto : MESTE, July 15, 2020. - 2 : Vol. 8. - pp. 157-163.

Style - Harvard Anglia:

Safonov, E., Kirsanov, S. \& Palamarenko, G., 2020. Prospects for the implementation of blockchain technology in Russia. MEST Journal, 15 July, 8(2), pp. 157-163.

Style - ISO 690 Numerical Reference:

Prospects for the implementation of blockchain technology in Russia. Safonov, Evgeny, Kirsanov, Sergey and Palamarenko, Galina. [ed.] Zoran Cekerevac. 2, Belgrade - Toronto : MESTE, July 15, 2020, MEST Journal, Vol. 8, pp. 157-163. 